\section{Neu bei conrad}

Der Vortrag „Das neue Strahlenschutzrecht in der praktischen Anwendung “ von Prof. Dr. Dr. Reinhard Loose steht ab sofort allen Mitgliedern auf conrad, der interaktiven Lernplattform der DRG, zur Verfügung.

Der Vortrag wurde am 10.11.2020 im MTRA-Programm der Reihe „Akademie

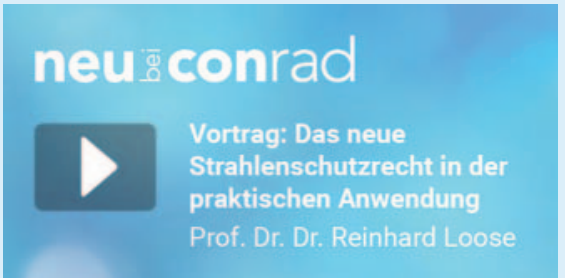

Online" gehalten und ist in der Materialsammlung „Neue Strahlenschutz-Gesetzgebung ab 2019“ enthalten.

Zum Vortrag gelangen Sie unter: www.conrad.drg.de 